Strength of religious faith in Peruvian adolescents and adults: psychometric evidence from the long and short version of the Santa Clara Strength of Religious Faith Questionnaire in Spanish

\begin{abstract}
Authors
Tomás Caycho-Rodríguez ${ }^{1}$, Lindsey W. Vilca ${ }^{2}$, Thomas G. Plante ${ }^{3}$, Andrea VivancoVidal $^{4}$, Daniela Saroli-Araníbar ${ }^{5}$, Carlos Carbajal-León ${ }^{1}$, Brian Norman Peña-Calero ${ }^{5}$, Michael White 6

\section{Institutional affiliation}

${ }^{1}$ Facultad de Ciencias de la Salud, Universidad Privada del Norte, Lima, Perú

${ }^{2}$ Facultad de Ciencias de la Salud, Universidad Peruana Unión, Lima, Perú

${ }^{3}$ Department of Psychology, Santa Clara University, Santa Clara, CA, USA

${ }^{4}$ Facultad de Psicología, Universidad Peruana de Ciencias Aplicadas, Lima, Perú

${ }^{5}$ Grupo de Estudios Avances en Medición Psicológica, Universidad Nacional Mayor de San Marcos, Lima, Perú

${ }^{6}$ Dirección General de Investigación, Universidad Peruana Unión, Perú
\end{abstract}

\title{
Correspondence author
}

Tomás Caycho-Rodríguez

Facultad de Ciencias de la Salud, Universidad Privada del Norte Av. Alfredo Mendiola 6062, Los Olivos, Lima, Perú

email: tomas.caycho@upn.pe 


\title{
Strength of religious faith in Peruvian adolescents and adults: psychometric evidence from the long and short version of the Santa Clara Strength of Religious Faith Questionnaire in Spanish
}

\begin{abstract}
The aim of this study was to evaluate the psychometric evidence of the original and brief version of the Santa Clara Strength of Religious Faith Questionnaire (SCSRFQ) in Spanish in a sample of 245 Peruvian adolescents and adults (mean age = 21.04 years, $\mathrm{SD}=3.07,47.8 \%$ male and $52.2 \%$ female), selected by non-probabilistic convenience sampling. Additionally, the Coronavirus Anxiety Scale and the Satisfaction with Life Scale were applied. Confirmatory Factor Analysis, internal consistency reliability methods, hierarchical sequence of variance models and Graded Response Model were used. Results indicate that both versions of the SCSRFQ showed robust psychometric properties: adequate unidimensional structure, adequate difficulty and discrimination parameters, and significant relationships with the measures of fear of COVID-19 and satisfaction with life. The original version of the SCSRFQ showed evidence of strict measurement invariance by gender and age; whereas the short version showed strict invariance by gender and configural invariance by age. Both versions showed acceptable reliability indices. In conclusion, the original and brief versions of the SCSRFQ show evidence of psychometric indicators that support their use to assess the strength of religious faith.
\end{abstract}

Keywords: reliability, strength of faith, invariance, validity 


\section{Introduction}

The religious landscape is dynamic and pluralistic in most Latin American countries, with a decrease in the number of people who identify themselves as Catholics, along with the growth of people who profess an evangelical faith tradition, and those who do not practice any religion (Pew Research Center 2014; Somma et al. 2017). This is not only a Latin American reality, as different studies suggest that in the last 40 years there is a decrease in religious affiliation in the United States and different European countries (Dein et al. 2020). Despite the steady decline in the number of people who identify themselves as religious in the Western world, religion still plays an important role in the lives of many people (Kranz et al. 2020). For example, in Peru, religious faith is very important for most Peruvians, where $92 \%$ believe in God, $72 \%$ consider themselves religious (WIN Gallup International 2017) and "being well with God" is one of the main sources of happiness (Alarcón 2002).

For some years now, the impact of religiosity and spirituality on the quality of life and well-being of people, whether healthy or ill, has been reported, promoting improved life satisfaction, greater hope, optimism, engagement with the local community, bonding with friends and family, as well as lower rates of anxiety, depression, psychological distress, and lower risk of mortality (Abu et al. 2018; Bravin et al. 2019; Burlacu et al. 2019; Darviri et al. 2016; Dunbar 2020; Lerman et al. 2018; $\mathrm{Ng}$ et al. 2017). The benefits of spiritual beliefs on mental health also affect physical health by decreasing the risk of contracting a disease and influencing the response to treatment (Del Castillo 2020).

Epidemiological models of virus spread do not consider factors such as religious values (Dein et al. 2020), which promote spiritual support for people in times of crisis (Fardin 2020). In the current COVID-19 pandemic, religiosity and spirituality have served to address the negative consequences of social isolation on mental health (Lucchetti et al. 2020). In addition, an increase in religious practices, such as time spent in prayer and other activities, has been observed (Boguszewski et al. 2020). In this regard, the number of searches for the word "prayer" on Google increased in 2020, doubled for every 80,000 newly diagnosed cases of COVID-19 (Bentzen 2020). This suggests an increase in the actual number of people practicing prayer (Dein et al. 2020). Likewise, a recent survey indicated that 55\% of Americans prayed for the COVID-19 pandemic to end, which included $15 \%$ who "Rarely or never prayed" and $24 \%$ of people who prayed for the pandemic to go away but had no religious affiliation (Pew Research Center 2020). Similarly, another survey indicated that $19 \%$ of Americans intensified their faith, while only 3\% reported that it got worse (Newport 2020).

Regarding religious faith, it has been suggested that it facilitates adaptation to diseases and the consequences derived from them (Kowalczyk et al. 2020), becoming a factor with important effects on health and well-being (Koenig et al. 2020). This is due to its benefits on the functioning of the immune system and vulnerability to viral infections, making the disease less severe and people have a faster recovery (Koenig 2020). Similarly, a recent study indicated that young people between the ages of 21 and 35 indicated that faith and prayer were of great importance in the context of the 
COVID-19 pandemic; likewise, $64 \%$ of women stated that their faith will protect them from the danger of the COVID-19 pandemic (Kowalczyk et al. 2020).

To effectively assess religious faith, as well as other spiritual and religious beliefs and behaviors, researchers need measures with adequate psychometric evidence. Many of these instruments, however, are specific to a particular type of religion, others assume that respondents have a religious affiliation or do not have sufficient empirical evidence to support their psychometric properties (Plante, 2010). Seeking to overcome these limitations, the Santa Clara Strength of Religious Faith Questionnaire (SCSRFQ; Plante and Boccaccini 1997) was developed as a measure of the strength of religious faith. The SCSRFQ defines faith as commitment to different spiritual and religious beliefs and institutions; while strength of faith refers to the importance of religious beliefs and practices in people's lives. These general definitions allow the SCSRFQ to assess one's faith independently of how it is defined in different religious traditions, which enables its use in different cultural contexts and without assuming that the respondent is religious or belongs to a specific religion, thus allowing the generalization and adaptability of the questionnaire (Plante 2021).

The SCSRFQ is a short self-report measure (the original version has 10 items), free to use, and easy to administer and score, making it useful for researchers and health professionals who wish to examine the degree of strength of religious faith or use it as a variable within their different investigations (Plante and Boccaccini 1997). In addition, the SCSRFQ is translated into different languages, such as English, Spanish,

Portuguese, Italian, Czech, Polish, German, Chinese, and Farsi (Plante 2021). Initially, the SCSORFQ was used in studies with patients with chronic diseases (e.g., Plante et al. 1999; Sherman et al. 1999) and has also been implemented in other populations, such as college students (Storch et al. 2004; Wnuk 2017), older adults (Cummings et al. 2015), people identified as gay, lesbian or bisexual (Walker and Longmire-Avital 2013), among others.

Several studies, in different cultural contexts, have shown that the SCSRFQ is a unidimensional measure of religious faith, with adequate reliability, that presents significant relationships with other variables such as religious life and orientation, intrinsic religious motivation, social provisions, social desirability, anxiety, emotional control, self-righteousness, optimism, spiritual experience, religious coping, negative and positive affect, religiosity and spirituality, spiritual well-being, depression and life satisfaction, among others (Akin et al. 2015; Cummings et al. 2015; Dianni et al. 2014; Freiheit et al. 2006; Koukounaras Liagkis and Ktenidis 2021; Lewis et al. 2001;

Pakpour et al. 2014; Plante and Boccaccini 1997; Plante et al. 1999; Sherman et al. 1999; Sherman et al. 2001; Wnuk 2017). Seeking to facilitate the use of the SCSRFQ in epidemiological research and the evaluation of patients with medical illnesses, a study conducted with samples of university students, women with cancer or cancer screening patients, and healthy women in a clinical setting developed a brief version consisting of items 2, 4, 5, 8, and 10 of the original questionnaire (SCSRFQ-SF; Plante et al. 2002). The items were selected on the basis of their high correlations with the total score of the original 10-item version, their moderate means and high standard deviations. This short version has also been shown to have a unidimensional structure, good internal 
consistency $($ Cronbach's alpha $=.95)$, high correlation with the full version of the questionnaire $(r=.95)$ and significant correlations with the organizational, nonorganizational and intrinsic dimensions of the Duke Religious Index ( $\mathrm{r}$ between -.71 to .85) (Plante et al. 2002). Other psychometric studies conducted on university students have obtained similar results (Storch et al. 2004; Storch et al. 2004).

The psychometric analyses of the original and brief version of the SCSRFQ have been carried out based on procedures characteristic of the Classical Test Theory (CTT). CTT procedures evaluate the scales as an integrated whole and assume that people have an inherent attribute, which we can measure through the numerical expression of an observed score, which is made up of the combination of the true score and the associated random error, where a lower variability of the score would indicate a higher precision in the measurement (observed score). In this sense, the CTT assumes that each item of the SCSRFQ has similar functioning and is equally accurate for measurements in people with low, medium or high levels of faith strength and, therefore, each item would provide us with the same amount of information (DeVellis 2016; Furr 2011). On the other hand, IRT overcomes the limitations of CTT (Embretson and Reise 2000) by assessing the relationships between the characteristics of the scale items (difficulty and discrimination), people's responses to the items, and the latent traits being measured (Steinberg and Thissen 2013). Thus, IRT procedures allow for estimating the precision (or greater information) with which each item measures a latent construct among people with different levels of that construct (Edelen and Reeve 2007). A study in older adults (Cummings et al. 2015) analyzed the original version of the SCSRFQ using IRT, and reported that all items allow for distinguishing between people with different levels of belief strength; furthermore, the SCSRFQ appears to more accurately measure low to moderate levels of belief strength, while poorly measuring very low and very high levels of belief. In this sense, the measurement of faith strength could be improved by understanding which items provide better information about people who have low, medium, or high levels of faith strength. The use of procedures derived from CTT and IRT would provide more robust psychometric results; however, no study has evaluated the psychometric properties of the Spanish translation of the original and the brief version of the SCSRFQ using both procedures in combination.

In this sense, the present study aimed to examine the reliability, validity evidence based on internal structure and the relationship with other variables (COVID19 anxiety and life satisfaction), and measurement invariance by gender and age of the original and brief version of the SCSRFQ using structural equation modeling, as well as the characteristics (difficulty and discrimination) of the items based on the IRT-derived Graded Response Model. The original and brief versions of the SCSRFQ are expected to have a unidimensional structure and high reliability estimates, as indicated by the literature (Plante 2021). Also, the SCSRFQ score is expected to correlate positively with life satisfaction (Cummings et al. 2015; Freiheit et al. 2006; Hebert et al. 2009; Wnuk 2017). Although there are no studies relating COVID-19 anxiety and faith strength, a positive relationship is expected, as noted by previous studies relating the latter variable to general anxiety symptoms (Plante et al. 2001; Plante et al. 2000). Similarly, the SCSRFQ items are expected to have adequate discrimination and 
difficulty parameters from IRT models, as indicated by the literature (Cummings et al. 2015).

On the other hand, the SCSRFQ has been used to compare the strength of faith between men and women, as well as between different age groups, with some studies indicating that women and older people have higher scores (DeBono and Kuschpel 2014), while others reported no gender differences (Storch et al. 2004). However, no measurement invariance studies of the SCSRFQ, which would test the equivalence of the measured construct between two or more groups to be sure that the same construct is assessed in each group and, therefore, the possible differences found between groups are true and not differences associated with the responses to the questionnaire items (Cheung and Rensvold 2002), have been previously conducted. Despite the absence of previous information on the invariance of the SCSRFQ measurement, it is expected that the questionnaire is invariant across different gender and age groups, as has been found in other questionnaires that assess aspects related to spirituality (Wink et al. 2021).

\section{Materials and Methods}

\section{Participants}

A total of 245 adolescents and adults from the city of Lima, Peru participated, selected by non-probabilistic convenience sampling. The number of participants was determined according to the criteria of Muthén and Muthén (2002), who indicated that between 150 and 300 participants is sufficient for the psychometric study of unidimensional scales. The participants had an average age of 21.04 years (S.D.=3.07), where $117(47.8 \%)$ were male and $128(52.2 \%)$ were female. Of the participants, $75.5 \%$ had a permanent job, $13.1 \%$ had a temporary job and $11.4 \%$ were unemployed. The 90.6\% were diagnosed with COVID-19 and $73.9 \%$ had family members diagnosed with the disease. In addition, $63.7 \%$ reported having been exposed to between 1 and 3 hours of information about COVID-19, while 54.7\% indicated having left home less than a day or two in the past two weeks. Finally, $70.2 \%$ reported living with vulnerable people (children, elderly, chronically ill).

\section{Instruments}

Santa Clara Strength of Religious Faith Questionnaire (SCSRFQ; Plante and Boccaccini 1997). This is a self-report measure of religious faith strength, originally consisting of 10 items with 4 Likert-type response options (1=strongly disagree to $4=$ strongly agree). The total score of the SCSRFQ ranges from 10 to 40 . The short version of the SCSRFQ is composed of 5 items (items 2, 4, 5, 8 and 10) derived from the original questionnaire (SCSRFQ-SF; Plante et al. 2002). Like the original version, the total score is obtained from the sum of all items and varies between 5 and 20. In both versions, higher scores express greater strength of religious faith.

Coronavirus Anxiety Scale (CAS, Lee 2020). This self-report measure is made up of 5 items to identify the frequency of physiological symptoms generated by 
thoughts and information related to COVID-19 during the last 2 weeks. The version validated for the general population of Peru (Caycho-Rodriguez et al. 2021) was used, where each item has 5 response options ranging from 0 (not at all) to 4 (almost every day). The sum of the scores for each item provides a total CAS score ranging from 0 to 20 , where a higher score indicates a higher frequency of anxiety symptoms related to COVID-19. In this study, the CAS had adequate internal consistency reliability $(\alpha=$ 93).

The Satisfaction with Life Scale (SWLS, Diener et al. 1985). This is made up of 5 items that assess a person's general feeling of satisfaction with his or her life. The version validated in Peru was used (Oliver et al. 2018). The items have 5 Likert-type response options ( $1=$ strongly disagree to $5=$ strongly agree), where the sum of the scores for each item provides a total score ranging from 5 to 25 . A higher score indicates greater overall satisfaction with life. In this study, the SWLS had adequate internal consistency reliability $(\alpha=.90)$.

\section{Procedure}

An instrumental study (Ato et al. 2013) was carried out by applying an online survey between July and August 2020. The survey was applied on the Google Forms platform and took approximately 15 minutes to complete. Due to the restrictions on social interaction imposed by the Peruvian government to mitigate the spread of COVID-19, the web link to the survey was shared via email and/or social networks (Facebook, Instagram, Twitter). The study was reviewed and approved by the Ethics Committee of the Universidad Privada del Norte and followed the ethical standards of the Declaration of Helsinki. In the first part of the survey, participants were informed about the objective of the study, the anonymous nature of their responses, and the use that would be made of the information collected. Electronic informed consent was obtained from the participants.

\section{Data analysis}

First, descriptive statistics were calculated for the SCSRFQ items (mean [M], standard deviation [SD], skewness [g1] and kurtosis [g2]). Second, two Confirmatory Factor Analyses (CFA) were performed. One to assess the internal structure of the full and brief version of the SCSRFQ and the other to assess the evidence of validity in relation to other constructs for both scales. In this second CFA, hypothetical models were tested, where the strength of faith was related to the degree of anxiety about COVID-19 and satisfaction with life. For both CFAs the Diagonally Weighted Least Squares with Mean and Variance corrected (WLSMV) estimator was used because the SCSRFQ items are ordinal in nature (Brown 2015). To evaluate the fit of the models, the chi-square test $(\chi 2)$ was used, as well as the RMSEA and SRMR indices, where values less than .05 indicate good fit, and between .05 and .08 an acceptable fit (Kline, 2015). In addition, the CFI and TLI indices were used, where values greater than .95 indicate good fit and greater than .90 an acceptable fit (Schumacker and Lomax 2015). To assess the internal consistency of the scale, Cronbach's alpha coefficient (Cronbach, 
1951) and the omega coefficient (McDonald 1999) were used, where a value of $\omega>.80$ is adequate (Raykov and Hancock 2005).

Third, the invariance of the full and short version of the SCSRFQ was evaluated according to the gender and age of the participants. For this purpose, a sequence of increasingly restrictive hierarchical variance models was proposed. Initially, configural invariance (reference model) was evaluated, followed by metric invariance (equality of factor loadings), scalar invariance (equality of factor loadings and intercepts) and finally strict invariance (equality of factor loadings, intercepts and residuals) was tested. To compare the sequence of models we first employed a formal statistical test: the chisquare difference $(\Delta \chi 2)$ where non-significant values ( $p>.05)$ suggest invariance between groups. Likewise, a modeling strategy was also employed, for which the difference in CFI $(\triangle \mathrm{CFI})$ was used, where values less than $<.010$ evidence model invariance, and the difference in RMSEA ( $\triangle$ RMSEA), where values less than $<.015$ evidence model invariance between groups (Chen 2007).

The SCSRFQ was also evaluated on the basis of Item Response Theory (IRT). With this in mind, a Graded Response Model (GRM, Samejima 1997) was employed, specifically an extension of the 2-parameter logistic model (2-PLM) for ordered polytomous items (Hambleton et al. 2010). For each item, two types of parameters were estimated, discrimination (a) and difficulty (b). The discrimination parameter (a) determines the slope at which item responses vary as a function of the level of the latent trait. The difficulty parameter (b) determines how much of the latent trait the item requires to be answered by the participants. Since the full and short version of the SCSRFQ have four response categories, three estimates of the difficulty parameter are obtained. The estimates for these three thresholds indicate the level of the latent variable at which an individual has a 50\% chance of scoring at or above the response category related to the threshold. Item information curves (IIC) and test information curves (TIC) were also calculated for both versions.

Data analysis was performed in the RStudio environment (RStudio Team 2018) for R (R Core Team 2019). The "lavaan" package (Rosseel 2012), the "semTools" package for factorial invariance (Jorgensen et al. 2018) and the "ltm" package for the GRM (Rizopoulos 2018) were used for the CFAs.

\section{Results}

\section{Descriptive analysis of the full version and abridged version items}

Table 1 shows that item 7 (My relationship with God is extremely important to me) has the highest mean score in the total sample $(M=2.64)$ and in the specific groups of males $(M=2.69)$, females $(M=2.59)$, adolescents $(M=2.78)$ and adults $(M=2.49)$. It is also observed that item 5 (I consider myself active in my faith or church) presents the lowest mean score in the total sample $(M=2.06)$ and in the specific groups of males $(M=2.10)$, females $(M=2.02)$, adolescents $(M=2.21)$ and adults $(M=1.90)$. In addition, all items present adequate skewness and kurtosis indices $( \pm 1.5)$ in the total sample and in all specific groups. 
[Insert table 1]

\section{Validity based on the internal structure of both scales}

Table 2 shows that the unidimensional model of the full version of the SCSRFQ evidences acceptable fit indices in the total sample $(\chi 2=99.19 ; \mathrm{df}=35 ; \mathrm{p}=.000 ; \mathrm{CFI}=.99$; $\mathrm{TLI}=.99 ; \mathrm{RMSEA}=.087)$, the sample of males $(\chi 2=67.94 ; \mathrm{df}=35 ; \mathrm{p}=.001 ; \mathrm{CFI}=.99$; $\mathrm{TLI}=.99 ; \mathrm{RMSEA}=.090)$, females $(\chi 2=85.16 ; \mathrm{df}=35 ; \mathrm{p}=.000 ; \mathrm{CFI}=.99 ; \mathrm{TLI}=.98$; RMSEA = .106), adolescents $(\chi 2=105.75 ; \mathrm{df}=35 ; \mathrm{p}=.000 ; \mathrm{CFI}=.99 ; \mathrm{TLI}=.98 ; \mathrm{RMSEA}$ $=.126)$ and adults $(\chi 2=67.10 ; \mathrm{df}=35 ; \mathrm{p}=.001 ; \mathrm{CFI}=.99 ; \mathrm{TLI}=.99 ; \mathrm{RMSEA}=.089)$. In addition, it can be seen that in the total sample and in the specific groups, the factor loadings are high and significant (see Table 4).

[Insert table 2]

Table 3 shows that the unidimensional model of the brief version of the SCSRFQ, presents acceptable adjustment indexes in the total sample $\left(\chi^{2}=14.19 ; \mathrm{df}=5 ; \mathrm{p}=.014\right.$; CFI $=.99 ; \mathrm{TLI}=.99 ; \mathrm{RMSEA}=.087)$, men $\left(\chi^{2}=6.28 ; \mathrm{df}=5 ; \mathrm{p}=.279 ; \mathrm{CFI}=.99 ; \mathrm{TLI}=.99\right.$; RMSEA = .047), women $\left(\chi^{2}=11.43 ; \mathrm{df}=5 ; \mathrm{p}=.043 ; \mathrm{CFI}=.99 ;\right.$ TLI $=.99 ;$ RMSEA $=$ $.101)$, adolescents $\left(\chi^{2}=2.11 ; \mathrm{df}=5 ; \mathrm{p}=.834 ; \mathrm{CFI}=1.00 ; \mathrm{TLI}=1.00 ; \mathrm{RMSEA}=.000\right)$ and adults $\left(\chi^{2}=18.19 ; \mathrm{df}=5 ; \mathrm{p}=.003 ; \mathrm{CFI}=.99 ; \mathrm{TLI}=.99 ; \mathrm{RMSEA}=.151\right)$. Likewise, the factor loadings of the items are high and significant in all groups (see Table 4).

[Insert table 3]

\section{Factorial invariance of both scales according to gender and age}

Regarding the full version of the SCSRFQ, the factor structure shows evidence of being strictly invariant between male and female groups, based on the sequence of invariance models posed: metric $(\Delta \chi 2=7.24, p=.612, \Delta \mathrm{CFI}=.007)$, scalar $(\Delta \chi 2=6.65$, $p=.673, \Delta \mathrm{CFI}=-.000)$ and strict $(\Delta \chi 2=7.50, p=.677, \Delta \mathrm{CFI}=.000)$ invariance. Similarly, the SCSRFQ also showed evidence of being strictly invariant between adolescents and adults: metric $(\Delta \chi 2=15.29, p=.083, \Delta \mathrm{CFI}=-.007)$, scalar $(\Delta \chi 2=19.31, p=.022, \Delta \mathrm{CFI}=-$ $.004)$ and strict $(\Delta \chi 2=12.69, p=.241, \Delta \mathrm{CFI}=.001)$ invariance. The results can be seen in Table 3.

Similarly, in the brief version of the SCSRFQ, the findings presented in Table 3 indicate that the factor structure has shown evidence of being strictly invariant between males and females: metric $(\Delta \chi 2=3.32, p=.504, \Delta \mathrm{CFI}=.001)$, scalar $(\Delta \chi 2=.87, p=.928$, $\Delta \mathrm{CFI}=-.000)$ and strict $(\Delta \chi 2=3.10, p=.684, \Delta \mathrm{CFI}=-.000)$ invariance. However, the scale only evidenced configural invariance between adolescents and adults: metric $(\Delta \chi 2=9.78$, $p=.044, \Delta \mathrm{CFI}=-.017)$, scalar $(\Delta \chi 2=11.65, p=.020, \Delta \mathrm{CFI}=-.012)$ and strict $(\Delta \chi 2=3.53$, $p=.617, \Delta \mathrm{CFI}=.011)$ invariance. 


\section{Reliability of both scales}

The full version of the SCSRFQ presents adequate reliability indices $(\alpha=.97 ; \omega$ $=.97)$ in the total sample, as well as in the groups of men $(\alpha=.98 ; \omega=.97)$, women $(\alpha=$ $.97 ; \omega=.97)$, adolescents $(\alpha=.97 ; \omega=.97)$ and adults $(\alpha=.98 ; \omega=.98)$. Similar results are observed when assessing the reliability of the brief version of the SCSRFQ in the total sample $(\alpha=.94 ; \omega=.92)$, men $(\alpha=.94 ; \omega=.92)$, women $(\alpha=.94 ; \omega=.93)$, adolescents $(\alpha=.94 ; \omega=.92)$, and adults $(\alpha=.95 ; \omega=.94)$. The results are observed in Table 4.

\section{[Insert table 4]}

\section{Item Response Theory Model: Graded Response Model (GRM)}

A graded response model (GRM), specifically a 2PLM model, was fitted for each version of the SCSRFQ. Table 5 shows that all item discrimination parameters for both versions are above the value of 1 , generally considered as good discrimination (Hambleton, van der Linden \& Wells, 2010). Regarding the difficulty parameters, in both versions, all threshold estimators increased monotonically, as expected.

\section{[Insert table 5]}

Figure 1 shows the IIC and TIC. Regarding the full version of the SCSRFQ, the IIC shows that items 4 and 6 are the most accurate in assessing the latent trait. In addition, the TIC shows that the factor is more reliable (accurate) in the range of the scale between -1 and 1.5. Regarding the brief version, the IIC shows that items 2 and 5 are the most accurate in assessing the latent trait. In addition, the TIC shows that the factor is more reliable (accurate) in the range of the scale between -1 and 1.5.

\section{[Insert figure 1]}

\section{Validity based on the relationship to other constructs}

Taking into account the literature review, several individual models were proposed to evaluate the relationship between the strength of faith construct and other constructs. Regarding the full version of the SCSRFQ, Figure 2 presents model 1 relating strength of faith and anxiety related to COVID-19, which has excellent fit indices $(\chi 2=128.02 ; \mathrm{df}=89 ; \mathrm{p}=.004 ; \mathrm{RMSEA}=.042 ; \mathrm{CFI}=.99 ; \mathrm{TLI}=.99)$ and both variables have a positive relationship $(r .26 ; \mathrm{p}<.01)$. In model 2 , the relationship between faith strength and life satisfaction presents adequate fit indices $(\chi 2=145.31 ; \mathrm{df}=89 ; \mathrm{p}$ $=.000 ; \mathrm{RMSEA}=.051 ; \mathrm{CFI}=.99 ; \mathrm{TLI}=.99)$, where both variables have a positive relationship $(r .38 ; \mathrm{p}<.01)$. 
Regarding the brief version of the SCSRFQ scale, Figure 3 shows that model 1 of the relationship between faith strength and anxiety related to COVID-19 presents adequate adjustment indexes $(\chi 2=43.77 ; \mathrm{df}=34 ; \mathrm{p}=.122 ; \mathrm{RMSEA}=.034 ; \mathrm{CFI}=.99$; TLI=.99), where both variables have a positive relationship $(r .29 ; \mathrm{p}<.01)$. Model 2 of the same figure shows the relationship between faith strength and life satisfaction, which presents adequate fit indices $(\chi 2=55.44 ; \mathrm{df}=34 ; \mathrm{p}=.012$; $\mathrm{RMSEA}=.051$; $\mathrm{CFI}=.99 ; \mathrm{TLI}=.99)$, where both variables have a positive relationship $(r .40 ; \mathrm{p}<.01)$.

\section{[Insert figure 3]}

\section{Discussion}

The SCSRFQ was created to provide a quick, simple, and useful measure of religious faith strength that can be used in research and practice by mental health professionals. Moreover, because its items do not refer to any specific religious orientation, it can be used in people with any religious affiliation. In this sense, the aim of the study was to examine the reliability, the evidence of validity based on the internal structure and the relationship with other variables, the invariance of the measurement according to gendr and age, as well as the characteristics (difficulty and discrimination) of the items of the original and brief version of the SCSRFQ in Spanish.

The unidimensional structure of the original (10 items) and brief (5 items) version of the SCSRFQ in Spanish had an adequate fit, and all items loaded significantly on the latent factor religious faith strength, both in the total sample and in the gender and age subgroups. Therefore, the present study replicates previous findings reported in the literature (Akin et al. 2015; Cummings et al. 2015; Dianni et al. 2014; Freiheit et al. 2006; Koukounaras et al. 2021; Lewis et al. 2001; Pakpour et al. 2014; Plante and Boccaccini 1997; Plante et al. 1999; Plante et al. 2002; Plante 2021; Sherman et al. 1999; Sherman et al. 2001; Storch et al. 2004; Wnuk 2017). Thus, each item would reflect only one latent construct and not another (Gefen 2003). If this were not the case and one or more items measured not only strength of faith but also another aspect related to spirituality, the total SCSRFQ score would contain this information and could not be used to interpret a person's position on the latent variable strength of faith (Ziegler and Hagemann, 2015). In addition, both versions of the SCSRFQ presented adequate values of reliability coefficients.

The results of the GRM analysis indicated that the discrimination parameters of the items were high (above 2) in both versions of the SCSRFQ, thus, all items are adequate to differentiate the responses of people with different levels of faith strength. In the original version, items 3, 4, 6 and 10 present the highest discrimination parameters and refer to the strength of faith as a source of inspiration, meaning, identity and decision making. Similarly, in the short version it was items 2 and 5 that have the highest discrimination parameters and also refer to the strength of faith as a source of meaning and decision making. This means that situations and/or items related to these themes will allow people to choose highly differentiated response alternatives even if some of them have similar levels of faith strength. 
Likewise, the difficulty parameters in both versions increased monotonically, indicating that as people have greater strength of faith, they will tend to choose positive and higher response alternatives. In the complete and brief version, items 1 and 2 are those that require a greater latent trait on the part of the participants so that they have a probability greater than or equal to $50 \%$ of being able to choose the alternative of agreeing totally with the statement. However, the rest of the response alternatives of these same items require amounts of the latent trait which do not differ highly from the last threshold (b3), so that these items end up being the least informative in both versions of the test. Despite this, the remaining items demonstrate excellent performance in the average population, so that the SCSRFQ can be used as a general measurement instrument across the different age groups tested.

Testing the unidimensionality and reliability of the SCSRFQ allows it to be used to investigate connections between faith strength and other mental health variables. In this sense, SCSRFQ scores correlated positively with COVID-19 anxiety and life satisfaction. These correlation patterns allow us to confirm previous hypotheses, providing additional evidence on the validity of the SCSRFQ among Peruvian youth and adults. In the case of the positive relationships between faith strength and COVID19 anxiety, it seems to suggest that the negative pressure of the pandemic on people's mental health intensified their faith along with other religious practices, such as prayer, thus seeking to have protection against the danger of the COVID-19 pandemic (Boguszewski et al. 2020; Kowalczyk et al. 2020; Newport 2020). Similarly, the relationship between the latent variables life satisfaction and faith strength would indicate that the latter is a positive and cognitive indicator for maintaining well-being (Koenig 2020; Wnuk 2017).

On the other hand, the present study extended previous findings by evaluating the measurement invariance of the original and brief versions of the SCSRFQ in Spanish. Results indicate that configural, metric, scalar, and strict invariance of the original and brief versions of the SCSRFQ was maintained in both genders.

Specifically, the configural invariance assessment suggests that youth and adults of both genders conceptualize religious strength of faith in the same unidimensional structure; metric invariance suggests that a change in the construct strength of faith causes the same change in SCSRFQ scores between the compared groups; scalar invariance indicates the relationship between the observed and latent SCSRFQ score is invariant; while strict invariance suggests that the SCSRFQ measures strength of faith with equivalent measurement error between men and women. Therefore, the unidimensional structure is equivalent and the original version of the SCSRFQ measures the same construct strength of faith across different gender groups (Van de Schoot et al. 2012). In addition, strict invariance assesses random error variability and systematic variability generated by unspecified sources of variation, thus also providing complementary information on reliability (Wu et al. 2007). In this sense, the strict invariance analysis indicates that the SCSRFQ items are equally reliable between men and women. Likewise, the brief version of the SCSRFQ showed strict invariance between the male and female groups; however, it only presented configural invariance when comparing the adolescent and adult groups. The absence of metric, scalar, and strict invariance between age groups does not provide a sound psychometric basis for using the brief version of the SCSRFQ to compare the means of the latent factor strength of faith between adolescents and adults. 
The study has some limitations that should be mentioned to guide the direction of future research. First, because the data were collected through non-probability sampling from a single city (Lima, Peru), the results may be limited, as they cannot be generalized to the entire population of young people and adults in Peru. In this sense, future studies should use nationally representative samples to confirm the findings presented here. In addition, further psychometric work could be conducted with clinical samples along with the general population to assess the criterion validity of the questionnaire. Second, the study design was cross-sectional and, therefore, the reported relationships between the variables faith strength, COVID-19 anxiety, and life satisfaction provide limited information on causality. Thus, longitudinal studies during this pandemic or others that may appear in the future may help to better understand the impact of religious faith strength on COVID-19 anxiety and life satisfaction. Third, the temporal stability of the SCSRFQ was not assessed, so it would be useful to assess this aspect in the future. Fourth, self-report measures may not be the best choice for investigating aspects related to spirituality and religiosity, because they involve a complex set of feelings and beliefs. In addition, self-report measures are associated with biases, such as social desirability (Rosenman et al. 2011). Therefore, it is recommended that future studies employ other methodologies to obtain information, such as in-depth interviews.

Despite the aforementioned limitations, this study is the first to evaluate the psychometric properties of the original and brief versions of the SCSRFQ in Spanish using traditional (structural equation modeling) and modern (IRT) procedures. In addition, the SCSRFQ is a measure that can be administered in a short period of time and provide information about the degree to which the strength of religious faith can be an important variable within the processes of mental health research and treatment. Regarding the former, the SCSRFQ may be useful in studies seeking a better understanding of the impact of spirituality on health outcomes. Additionally, people with greater faith strength may be likely to be part of mental health interventions that include spiritual or religious dimensions (Tan 2013). For example, cognitive-behavioral therapies that have incorporated spiritual beliefs and practices have been promoted for some years and are considered empirically validated interventions for members of different religious groups (Hook et al. 2010; Koenig and Al Shohaib 2014).

\section{Conclusion}

The quality of research depends, to a certain extent, on the precision of the instruments used to collect information, even more so if they evaluate complex phenomena related to spirituality, such as faith. In this sense, the findings of the validation process of the original and brief versions of the SCSRFQ in Spanish allowed us to establish that the measurement of a complex construct such as the strength of faith can be carried out with high levels of psychometric quality. Thus, both versions of the SCSRFQ are valid and reliable measures to assess the strength of religious faith in young people and adults.

\section{Funding:}

This research received no external funding 


\section{Author Contributions}

Conception and design of the work, writing - original draft preparation, supervision, TC-R; analysis and interpretation of data, LWV and BNP-C; acquisition of data, AV-V, DS-A and CC-L; writing, review \& editing, TGP and MW.

\section{Data Availability Statement:}

The data presented in this study are available on request from the corresponding author.

\section{Conflicts of Interest}

The authors have no conflict of interest

\section{References}

Abu Hawa O., Ulbricht Christine, Ding Eric, Allison, Jeroan J., Salmoirago-Blotcher, Elena, Goldberg, Robert. J., and Kiefe, Catarina I. 2018. Association of religiosity and spirituality with quality of life in patients with cardiovascular disease: a systematic review. Quality of Life Research 27(11): 2777-97. https://doi.org/10.1007/s11136-018-1906-4

Akin Ahmet, Turan, Mehmet Emin, and Altundağ Yunus, 2015. The validity and reliability of turkish version of the Santa Clara Strength of Religious Faith Questionnaire. Journal of Educational \& Instructional Studies in the World, 5(1): $35-8$.

Alarcón Reynaldo. 2002. Fuentes de felicidad: ¿Qué hace feliz a la gente? Revista de Psicología, 20(2): 169-96.

Ato Manuel, López-García Juan J., and Benavente Ana. 2013. Un sistema de clasificación de los diseños de investigación en psicología. Anales de Psicología 29(3), 1038-59. http://dx.doi.org/10.6018/analesps.29.3.178511

Bentzen Jeanet. 2020. In crisis, we pray: Religiosity and the COVID-19 pandemic. Working paper. https://papers.ssrn.com/sol3/papers.cfm?abstract_id=3615587

Boguszewski Rafal., Makowska Marta, Bożewicz Marta, and Podkowińska Monika. 2020. The COVID-19 Pandemic's Impact on Religiosity in Poland. Religions 11(12): 646. https://doi.org/10.3390/rel11120646

Bravin Ariane Moysés, Trettene, Armando dos Santos, de Andrade Luis Gustavo Modelli, Popim, and Regina Célia. 2019. Benefits of spirituality and/or religiosity in patients with Chronic Kidney Disease: an integrative review. Revista Brasileira de Enfermagem 72(2): 541-51. https://doi.org/10.1590/00347167-2018-0051

Brown Timothy A. 2015. Confirmatory Factor Analysis for Applied Research, Second Edition. Guilford Publications. Retrieved from https://books.google.com.pe/books?id=tTL2BQAAQBAJ 
Burlacu Alexandru, Artene Bogdan, Nistor Ionut, Buju, Smaranda, Jugrin Daniel, Mavrichi Ionut, and Covic Adrian. 2019. Religiosity, spirituality and quality of life of dialysis patients: a systematic review. International Urology and Nephrology 51(5): 839-50. https://doi.org/10.1007/s11255-019-02129-x

Chen Fang Fang. 2007. Sensitivity of goodness of fit indexes to lack of measurement invariance. Structural Equation Modeling 14(3): 464-504. https://doi.org/10.1080/10705510701301834

Cheung Gordon W., and Rensvold Roger B. 2002. Evaluating goodness-of-fit indexes for testing measurement invariance. Structural Equation Modeling 9(2): 233-55. https://doi.org/10.1207/S15328007SEM0902_5

Crocker Linda. 1986. Introduction to Classical and Modern Test Theory. New York, NY: Holt, Rinehart and Winston.

Cronbach Lee J. 1951. Coefficient alpha and the internal structure of tests. Psychometrika 16(3): 297-334. https://doi.org/10.1007/BF02310555

Cummings Jeremy P., Carson Cody S., Shrestha Srijana, Kunik Mark E., Armento María E., Stanley Melinda A., and Amspoker Amber B. 2015. Santa Clara Strength of Religious Faith Questionnaire: psychometric analysis in older adults. Aging \& Mental Health 19(1): 86-97. https://doi.org/10.1080/13607863.2014.917606

Darviri Christina, Artemiadis Artemios, Tigani Xanthi, Darvyri Panagiota, and Gnardellis, Charalambos. 2016. Religiosity as a predictor of mortality: A retrospective cohort study in 1519 rural citizens in Greece. Psychology \& Health 31(9): 1080-90. https://doi.org/10.1080/08870446.2016.1178744

DeBono Kenneth G., and Kuschpel Anja. 2014. Gender Differences in Religiosity: The Role of Self-Monitoring. North American Journal of Psychology 16(2), 415-25.

Dein Simon, Loewenthal Kate, Lewis Christopher Alan, and Pargament Kenneth I. 2020. COVID-19, mental health and religion: An agenda for future research. Mental Health, Religion \& Culture 23: 1-9. http://dx.doi.org/10.1080/13674676.2020.1768725

Del Castillo Fides A. 2020. Health, spirituality and Covid-19: Themes and insights. Journal of Public Health: fdaa185. https://doi.org/10.1093/pubmed/fdaa185

DeVellis Robert F. 2016. Scale development: Theory and applications, Vol. 26. Sage publications.

Dianni Maria, Proios Miltiadis, and Kouthouris Charilaos. 2014. Structural validity of 'Santa Clara strength of religious faith questionnaire'in greek sample. Religions 5(1): 157-64. https://doi.org/10.3390/rel5010157

Dunbar R. I. M. (2020). Religiosity and religious attendance as factors in wellbeing and social engagement. Religion, Brain \& Behavior: 11(1): 17-26. https://doi.org/10.1080/2153599X.2020.1712618 
Edelen Maria Orlando, and Reeve Bryce B. 2007. Applying item response theory (IRT) modeling to questionnaire development, evaluation, and refinement. Quality of Life Research 16(1): 5-18. https://doi.org/10.1007/s11136-007-9198-0

Embredson Susan E., \& Reise Steven P. 2000. Item response theory for psychologists. Mahway, NJ: Erlbaum

Fardin Mohammad Ali. 2020. COVID-19 epidemic and spirituality: A Review of the benefits of religion in times of crisis. Jundishapur Journal of Chronic Disease Care 9(2): e104260. http://dx.doi.org/10.5812/jjcdc.104260

Freiheit Stacy R, Sonstegard Kaela, Schmitt Alexis, and Vye Christopher. 2006. Religiosity and spirituality: A psychometric evaluation of the Santa Clara Strength of Religious Faith Questionnaire. Pastoral Psychology 55(1): 27-33. https://doi.org/10.1007/s11089-006-0029-y

Furr, R. Michael. 2011. Scale Construction and Psychometrics for Social and Personality Psychology. New Delhi, IN: Sage Publications.

Hambleton Ronald K., van der Linden Wim J, and Wells Craig S. 2010. IRT models for the analysis of polytomously scored data: Brief and selected history of model building advances. In Handbook of polytomous item response models. Edited by Michael L Nering and Remo Ostini. New York, NY: Routledge, pp. 21-42.

Hebert Randy, Zdaniuk Bozena, Schulz Richard, and Scheier Michael. 2009. Positive and negative religious coping and well-being in women with breast cancer. Journal of Palliative Medicine 12(6): 537-45. https://doi.org/10.1089/jpm.2008.0250

Hook Joshua N., Worthington Jr Everett L, Davis Don E., Jennings David J., Gartner, Aubrey L, and Hook Jan P. 2010. Empirically supported religious and spiritual therapies. Journal of Clinical Psychology 66(1): 46-72. https://doi.org/10.1002/jclp.20626

Jorgensen Terrence D., Pornprasertmanit Sunthud, Schoemann Alexander M, and Rosseel Yves. 2018. semTools: Useful tools for structural equation modeling. $R$ package version 0.5-1. https://CRAN.R-project.org/package=semTools

Kline Rex B. 2015. Principles and Practice of Structural Equation Modeling, 4th ed. New York, NY: The Guilford Press.

Koenig Harold G. 2020. Maintaining health and well-being by putting faith into action during the COVID-19 pandemic. Journal of Religion and Health 59: 2205-14. https://doi.org/10.1007/s10943-020-01035-2

Koenig Harold G, Al-Zaben Faten, and VanderWeele Tyler J. 2020. Religion and psychiatry: Recent developments in research. BJPsych Advances 26(5): 262-72. https://doi.org/10.1192/bja.2019.81

Koenig Harold G., and Al Shohaib Saad. 2014. Health and Well-Being in Islamic Societies. New York, NY: Springer. https://doi.org/10.1007/978-3-319-05873-3 
Koukounaras Liagkis Marios, and Ktenidis Zisis. 2021. Evaluating the Francis Scale of Attitudes Towards Christianity (FSATC) and the Santa Clara Strength of Religious Faith Questionnaire (SCSRFQ) in the Greek Orthodox context. Mental Health, Religion \& Culture: 1-11. https://doi.org/10.1080/13674676.2020.1770711

Kowalczyk Oliwia, Roszkowski Krzysztof, Montane Xavier, Pawliszak Wojciech, Tylkowski Bartosz, and Bajek Anna. 2020. Religion and Faith Perception in a Pandemic of COVID-19. Journal of Religion and Health 59(6): 2671-77. https://doi.org/10.1007/s10943-020-01088-3

Kranz Dirk, Niepel Christoph, Botes Elouise, and Greiff Samuel. 2020. Religiosity predicts unreasonable coping with COVID-19. Psychology of Religion and Spirituality: 1-5. https://doi.org/10.1037/rel0000395

Lerman Shir, Jung Molly, Arredondo Elva M., Barnhart Janice M., Cai Jianwen, Castañeda Sheila F, Daviglus Martha L., Espinoza Rebeca A., Giachello Aida L., Molina Kristine M., Perreira Krista, Salgado Hugo, Wassertheil-Smoller Sylvia, Kaplan Robert C. 2018. Religiosity prevalence and its association with depression and anxiety symptoms among Hispanic/Latino adults. PloS one 13(2): e0185661. https://doi.org/10.1371/journal.pone.0185661

Lewis, Christopher Alan, Shevlin Mark, McGuckin Conor, Navratil Marek. 2001. The Santa Clara strength of religious faith questionnaire: Confirmatory factor analysis. Pastoral Psychology 49(5): 379-84. https://doi.org/10.1023/A:1010370728546

Lucchetti Giancarlo, Góes Leonardo Garcia, Amaral Stefani Garbulio, Ganadjian Gabriela Terzian, Andrade Isabelle, de Araújo Almeida Paulo Othávio, do Carmo Victor Mendes, and Manso Maria Elisa Gonzalez. 2020. Spirituality, religiosity and the mental health consequences of social isolation during Covid19 pandemic. The International Journal of Social Psychiatry:1-8. http://dx.doi.org/10.1177/0020764020970996

McDonald Roderick P. 1999. Test Theory: A Unified Treatment. Taylor \& Francis.

Newport Frank. 2020, April 6. Religion and the COVID-19 Virus in the U.S. Gallup. https://news.gallup.com/opinion/polling-matters/307619/religion-covidvirus.aspx

Ng Guan Chong, Mohamed Salina, Sulaiman Ahmad Hatim, and Zainal Nor Zuraida, 2017. Anxiety and depression in cancer patients: the association with religiosity and religious coping. Journal of Religion and Health 56(2): 575-90. https://doi.org/10.1007/s10943-016-0267-y

Oliver Amparo, Galiana Laura, and Bustos Varinia. 2018. Validación de la Escala de Satisfacción con la Vida y su relación con las dimensiones del Autoconcepto en universitarios peruanos. Persona 21(2): 29-44. https://doi.org/10.26439/persona2018.n021.3018 
Pakpour Amir H., Plante Thomas G., Saffari Mohsen, and Fridlund Bengt. 2014. The Santa Clara strength of religious faith questionnaire (SCSORF): A validation study on Iranian Muslim patients undergoing dialysis. Journal of Religion and Health 53(6): 1885-97. https://doi.org/10.1007/s10943-014-9856-9

Pew Research Center. (2020, March 30). Most Americans say coronavirus outbreak has impacted their lives. https://www.pewsocialtrends.org/2020/03/30/mostamericans-saycoronavirus-outbreak-has-impacted-their-lives/

Plante Thomas G. 2021. The Santa Clara Strength of Religious Faith Questionnaire (SCSRFQ): A Brief, Nondenominational, and Multicultural Assessment Tool. In Assessing Spirituality in a Diverse World. Edited by Amy L AI, Paul Wink, Raymond F Paloutzian, and Kevin A. Harris. Springer, Cham, pp. 445-466.

Plante Thomas G., and Boccaccini Marcus T. 1997. The Santa Clara strength of religious faith questionnaire. Pastoral Psychology 45(5): 375-87. https://doi.org/10.1007/BF02230993

Plante Thomas G., Saucedo Beatriz, and Rice Chelsea. 2001. The association between strength of religious faith and coping with daily stress. Pastoral Psychology 49(4): 291-300. https://doi.org/10.1023/A:1004819505286

Plante Thomas G., Vallaeys Charlotte L., Sherman Allen C., and Wallston Kenneth A. 2002. The development of a brief version of the Santa Clara Strength of Religious Faith Questionnaire. Pastoral Psychology 50(5): 359-68. https://doi.org/10.1023/A:1014413720710

Plante Thomas G., Yancey Scott., Sherman Allen, and Guertin Mira. 2000. The association between strength of religious faith and psychological functioning. Pastoral Psychology 48(5): 405-12. https://doi.org/10.1023/A:1022040605141

Plante Thomas G., Yancey Scott, Sherman Allen, Guertin Mira, and Pardini Dustin. 1999. Further validation for the Santa Clara strength of religious faith questionnaire. Pastoral Psychology 48(1): 11-21. https://doi.org/10.1023/A:1021950628088

R Core Team. (2019). A language and environment for statistical computing. Vienna, Austria: R Foundation for Statistical Computing. http://www.r-project.org/

Raykov Tenko, and Hancock Gregory R. 2005. Examining change in maximal reliability for multiple-component measuring instruments. British Journal of Mathematical and Statistical Psychology 58(1): 65-82. https://doi.org/10.1348/000711005X38753

Rizopoulos Dimitris. 2006 ltm: An R package for latent variable modelling and item response theory analyses. Journal of Statistical Software 17(5): 1-25. https://doi.org/10.18637/jss.v017.i05

Rosenman Robert, Tennekoon Vidhura, and Hill Laura G. 2011. Measuring bias in selfreported data. International Journal of Behavioural and Healthcare Research 2(4): 320-32. https://doi.org/10.1504/IJBHR.2011.043414 
Rosseel Yves. 2012. lavaan: An R Package for Structural Equation Modeling. Journal of Statistical Software 48(2): 1-36. https://doi.org/10.18637/jss.v048.i02

RStudio Team. (2018). RStudio: Integrated Development Environment for R. Boston, MA: RStudio, Inc. http://www.rstudio.com/

Samejima Fumiko. 1997. Graded response model. In Handbook of modern Item Response Theory. Edited by Wim J. van der Linden and Ronald K. Hambleton. New York, NY: Springer, pp. 85-100.

Schumacker Randall E., and Lomax, Richard G. 2015. A Beginner's Guide to Structural Equation Modeling: Fourth Edition, 4th ed. New York, NY: Routledge.

Sherman Allen C., Plante Thomas G., Simonton Stephanie., Adams Dawn C., Burris S. Kaay, and Harbison Casey. 1999. Assessing religious faith in medical patients: Cross-validation of the Santa Clara Strength of Religious Faith Questionnaire. Pastoral Psychology 48(2): 129-41. https://doi.org/10.1023/A:1022094727122

Sherman Allen C., Simonton Stephanie, Adams Dawn C., Latif Umaira, Plante Thomas G., Burns S. Kaay, and Poling Tom. 2001. Measuring religious faith in cancer patients: Reliability and construct validity of the Santa Clara Strength of Religious Faith Questionnaire. Psycho-Oncology 10(5): 436-43. https://doi.org/10.1002/pon.523

Somma Nicolás M., Bargsted Matías A., and Valenzuela Eduardo. 2017. Mapping religious change in Latin America. Latin American Politics and Society 59(1): 119-42. https://doi.org/10.1111/laps.12013

Steinberg Lynne, and Thissen David. 2013. Item response theory. In Oxford library of psychology. The Oxford handbook of research strategies for clinical psychology. Edited by Jonathan S Comer and Philip C. Kendall. Oxford University Press, pp. 336-73.

Storch Eric A., Roberti Jonathan W., Bagner, Daniel M., Lewin, Adam B., Baumeister, Audrey L., and Geffkend, GaryR. 2004. Further Psychometric Properties of the Santa Clara Strength of Religious Faith Questionnaire-Short Form. Journal of Psychology \& Christianity 23(1): 51-53.

Storch Eric A., Roberti, Jonathan W., Bravata Erica., and Storch Jason B. 2004. Psychometric investigation of the Santa Clara strength of religious faith questionnaire—Short-form. Pastoral Psychology 52(6): 479-83. https://doi.org/10.1023/B:PASP.0000031526.64795.41

Tan Siang-Yang. 2013. Addressing religion and spirituality from a cognitivebehavioral perspective. In APA handbook of psychology, religion, and spirituality: Vol. 2. An applied psychology of religion and spirituality. Edited by Kenneth I. Pargament. Washington, DC: American Psychological Association, pp. 169 187. http://dx.doi.org/10.1037/14046-008

Van de Schoot Rens, Lugtig Peter, and Hox Joop. 2012. A checklist for testing measurement invariance. European Journal of Developmental Psychology 9(4): 486-92. https://doi.org/10.1080/17405629.2012.686740 
Walker, Ja'Nina J., and Longmire-Avital, Buffie. 2013. The impact of religious faith and internalized homonegativity on resiliency for black lesbian, gay, and bisexual emerging adults. Developmental Psychology 49(9): 1723-31. https://doi.org/10.1037/a0031059

WIN Gallup International (2017). Religion Prevails in the World. WIN/Gallup International. https://www.gallup-international.bg/en/36009/religion-prevails-inthe-world/

Ai Amy L., Wink Paul, Paloutzian Raymond F. and Harris Kevin A. 2021. Assessing Spirituality in a Diverse World. Springer, Cham.

Wnuk Marcin. 2017. A psychometric evaluation of the Santa Clara strength of religious faith questionnaire among students from Poland and Chile. Pastoral Psychology 66(4): 551-62. https://doi.org/10.1007/s11089-017-0754-4

Wu Amery D., Zhen Li, and Zumbo Bruno D. 2007. Decoding the meaning of factorial invariance and updating the practice of multi-group confirmatory factor analysis: A demonstration with TIMSS data. Practical Assessment, Research, and Evaluation 12(1): 3. https://scholarworks.umass.edu/pare/vol12/iss1/3

Ziegler Matthias, and Hagemann Dirk. 2015. Testing the unidimensionality of items. European Journal of Psychological Assessment 31: 231-7. https://doi.org/10.1027/1015-5759/a000309 
Table 1

Descriptive analysis of the items in the total sample and in specific groups of both scales.

\begin{tabular}{|c|c|c|c|c|c|c|c|c|c|c|c|c|c|c|c|c|c|c|c|c|}
\hline \multirow{2}{*}{ Items } & \multicolumn{4}{|c|}{ Total sample $(n=245)$} & \multicolumn{4}{|c|}{ Men $(n=117)$} & \multicolumn{4}{|c|}{ Women $(n=128)$} & \multicolumn{4}{|c|}{ Adolescents $(\mathrm{n}=128)$} & \multicolumn{4}{|c|}{ Adults $(n=117)$} \\
\hline & M & SD & $\mathrm{g} 1$ & $\mathrm{~g} 2$ & M & SD & $\mathrm{g} 1$ & $\mathrm{~g} 2$ & $\mathrm{M}$ & SD & $\mathrm{g} 1$ & $\mathrm{~g} 2$ & M & SD & $\mathrm{g} 1$ & $\mathrm{~g} 2$ & $\mathrm{M}$ & SD & $\mathrm{g} 1$ & g2 \\
\hline F1 & 2.54 & 1.07 & -.16 & -1.23 & 2.64 & & -.22 & & 2.45 & & -.13 & & & 1.06 & -.21 & -1.17 & 2.45 & 1.07 & -.10 & -1.28 \\
\hline $\mathrm{F} 2^{\mathrm{a}}$ & 2.10 & 1.03 & .48 & -.97 & 2.16 & 1.04 & .31 & -1.15 & 2.05 & 1.03 & .64 & -.74 & 2.25 & 1.06 & .31 & -1.13 & 1.94 & .98 & .67 & -.68 \\
\hline $\mathrm{F} 3$ & 2.44 & 1.07 & .04 & -1.26 & 2.46 & 1.09 & .00 & -1.30 & 2.41 & 1.06 & .09 & -1.22 & 2.52 & 1.04 & -.10 & -1.15 & 2.35 & 1.11 & .21 & -1.30 \\
\hline $\mathrm{F} 4^{\mathrm{a}}$ & 2.42 & 1.00 & .04 & -1.22 & 2.44 & 1.05 & -.03 & -1.21 & 2.39 & 1.06 & .11 & -1.22 & 2.45 & 1.07 & .02 & -1.24 & 2.38 & 1.04 & .06 & -1.20 \\
\hline $\mathrm{F} 5^{\mathrm{a}}$ & 2.06 & 100 & .47 & -.94 & 2.10 & 1.02 & .38 & -1.07 & 2.02 & .98 & .55 & -.77 & 2.21 & 1.00 & .26 & -1.06 & 1.90 & .96 & .73 & -.57 \\
\hline F6 & 2.40 & 1.04 & .08 & -1.18 & 2.40 & 1.05 & .06 & -1.21 & 2.41 & 1.03 & .10 & -1.14 & 2.52 & 1.05 & -.02 & -1.20 & 2.28 & 1.02 & .19 & -1.11 \\
\hline F7 & 2.64 & 1.12 & -.20 & -1.34 & 2.69 & 1.16 & -.24 & -1.41 & 2.59 & 1.09 & -.18 & -1.26 & 2.78 & 1.09 & -.36 & -1.18 & 2.49 & 1.14 & -.03 & -1.43 \\
\hline $\mathrm{F}^{\mathrm{a}}$ & 2.39 & 1.04 & .10 & -1.17 & 2.43 & 1.07 & .04 & -1.26 & 2.35 & 1.01 & -.16 & -1.07 & 2.51 & 1.03 & -.02 & -1.14 & 2.26 & 1.04 & .25 & -1.13 \\
\hline F9 & 2.43 & 1.06 & .00 & -1.24 & 2.50 & 1.05 & -.10 & -1.19 & 2.37 & 1.07 & .10 & -1.26 & 2.53 & 1.04 & -.12 & -1.17 & 2.32 & 1.08 & .15 & -1.27 \\
\hline $\mathrm{F} 10^{\mathrm{a}}$ & 2.38 & 1.07 & .16 & -1.23 & 2.44 & 1.11 & .06 & -1.35 & 2.32 & 1.04 & .25 & -1.09 & 2.57 & 1.09 & -.05 & -1.31 & 2.17 & 1.02 & .39 & -.97 \\
\hline
\end{tabular}

Note. $M=$ Mean; $S D=$ Standard Deviation; $g l=$ Skewness; $g 2=$ Kurtosis; ${ }^{\text {a }}$ Also part of the short form of the scale 


\section{Table 2}

Fit indices and invariance models by gender and age of the full version

\begin{tabular}{|c|c|c|c|c|c|c|c|c|c|c|c|c|}
\hline Unidimensional model & $\chi^{2}$ & df & $p$ & SRMR & TLI & CFI & RMSEA & $\Delta \chi^{2}$ & $\Delta \mathrm{df}$ & $p$ & $\Delta \mathrm{CFI}$ & $\triangle \mathrm{RMSEA}$ \\
\hline \multicolumn{13}{|l|}{ Total sample } \\
\hline Unidimensional model & 99.19 & 35 & .000 & .019 & .99 & .99 & .087 & - & - & - & - & - \\
\hline \multicolumn{13}{|l|}{ By gender } \\
\hline Men & 67.94 & 35 & .001 & .023 & .99 & .99 & .090 & - & - & - & - & - \\
\hline Women & 85.16 & 35 & .000 & .027 & .99 & .99 & .106 & - & - & - & - & - \\
\hline Configural & 82.81 & 70 & .140 & .024 & .99 & .99 & .039 & - & - & - & - & - \\
\hline Metric & 79.30 & 79 & .469 & .032 & 1.00 & 1.00 & .006 & 7.24 & 9 & .612 & .007 & -.033 \\
\hline Scalar & 86.83 & 88 & .515 & .034 & 1.00 & 1.00 & .000 & 6.65 & 9 & .673 & .000 & -.006 \\
\hline Strict & 94.13 & 98 & .592 & .036 & 1.00 & 1.00 & .000 & 7.50 & 10 & .677 & .000 & .000 \\
\hline \multicolumn{13}{|l|}{ By age } \\
\hline Adolescents (17 to 20 years old) & 105.75 & 35 & .000 & .029 & .99 & .99 & .126 & - & - & - & - & - \\
\hline Adults (21 to 35 years old) & 67.10 & 35 & .001 & .026 & .99 & .99 & .089 & - & - & - & - & - \\
\hline Configural & 88.32 & 70 & .069 & .026 & .98 & .98 & .046 & - & - & - & - & - \\
\hline Metric & 110.25 & 79 & .012 & .043 & .97 & .98 & .057 & 15.29 & 9 & .083 & -.007 & .011 \\
\hline Scalar & 125.52 & 88 & .000 & .046 & .97 & .97 & .059 & 19.31 & 9 & .022 & -.004 & .002 \\
\hline Strict & 134.04 & 98 & .009 & .050 & .98 & .97 & .055 & 12.69 & 10 & .241 & .001 & -.004 \\
\hline
\end{tabular}

Note: $\chi 2$ = Chi square; $\mathrm{df}=$ degrees of freedom; SRMR: Standardized Root Mean Square Residual; TLI = Tucker-Lewis Index; CFI =

Comparative Fit Index; RMSEA = Root Mean Square Error of Approximation; $\Delta \chi 2=$ Differences in Chi square; $\Delta \mathrm{df}=$ Differences in degrees of freedom; $\triangle \mathrm{RMSEA}=$ Change in Root Mean Square Error of Approximation; $\Delta \mathrm{CFI}=$ Change in Comparative Fix Index. 


\section{Table 3}

Fit indices and invariance models according to gender and age of the brief version

\begin{tabular}{|c|c|c|c|c|c|c|c|c|c|c|c|c|}
\hline Unidimensional model & $\chi^{2}$ & $\mathrm{df}$ & $p$ & SRMR & TLI & CFI & RMSEA & $\Delta \chi^{2}$ & $\Delta \mathrm{df}$ & $p$ & $\Delta \mathrm{CFI}$ & $\triangle \mathrm{RMSEA}$ \\
\hline \multicolumn{13}{|l|}{ Total sample } \\
\hline Unidimensional model & 14.19 & 5 & .014 & .015 & .99 & .99 & .087 & - & - & - & - & - \\
\hline \multicolumn{13}{|l|}{ By gender } \\
\hline Men & 6.28 & 5 & .279 & .015 & .99 & .99 & .047 & - & - & - & - & - \\
\hline Women & 11.43 & 5 & .043 & .019 & .99 & .99 & .101 & - & - & - & - & - \\
\hline Configural & 10.63 & 10 & .386 & .017 & .998 & .999 & .023 & - & - & - & - & - \\
\hline Metric & 12.85 & 14 & .538 & .026 & 1.00 & 1.00 & .000 & 3.32 & 4 & .504 & .001 & -.023 \\
\hline Scalar & 13.83 & 18 & .740 & .027 & 1.00 & 1.00 & .000 & .87 & 4 & .928 & .000 & .000 \\
\hline Strict & 16.98 & 23 & .810 & .031 & 1.00 & 1.00 & .000 & 3.10 & 5 & 684 & .000 & .000 \\
\hline \multicolumn{13}{|l|}{ By age } \\
\hline Adolescents (17 to 20 years old) & 2.11 & 5 & .834 & .008 & 1.00 & 1.00 & .000 & - & - & - & - & - \\
\hline Adults (21 to 35 years old) & 18.19 & 5 & .003 & .031 & .99 & .99 & .151 & - & - & - & - & - \\
\hline Configural & 13.61 & 10 & .191 & .018 & .989 & .994 & .055 & - & - & - & - & - \\
\hline Metric & 28.85 & 14 & .011 & .041 & .967 & .977 & .093 & 9.78 & 4 & .044 & -.017 & .038 \\
\hline Scalar & 39.89 & 18 & .002 & .049 & .962 & .965 & .100 & 11.65 & 4 & .020 & -.012 & .007 \\
\hline Strict & 38.16 & 23 & .024 & .053 & .979 & .976 & .074 & 3.53 & 5 & .617 & .011 & -.026 \\
\hline
\end{tabular}

Note: $\chi 2$ = Chi square; $\mathrm{df}=$ degrees of freedom; SRMR: Standardized Root Mean Square Residual; TLI = Tucker-Lewis Index; CFI =

Comparative Fit Index; RMSEA = Root Mean Square Error of Approximation; $\Delta \chi 2=$ Differences in Chi square; $\Delta \mathrm{df}=$ Differences in degrees of freedom; $\triangle \mathrm{RMSEA}=$ Change in Root Mean Square Error of Approximation; $\Delta \mathrm{CFI}=$ Change in Comparative Fix Index. 
Table 4

Standardized factor weights of the items and reliability of the scale according to gender, age and total sample.

\begin{tabular}{|c|c|c|c|c|c|c|c|c|c|c|}
\hline \multirow{3}{*}{ Items } & \multicolumn{2}{|c|}{ Total sample $(n=245)$} & \multicolumn{2}{|c|}{$\operatorname{Men}(n=117)$} & \multicolumn{2}{|c|}{ Women $(n=128)$} & \multicolumn{2}{|c|}{ Adolescents $(\mathrm{n}=128)$} & \multicolumn{2}{|c|}{ Adults $(n=117)$} \\
\hline & $\begin{array}{c}\text { Full } \\
\text { version }\end{array}$ & $\begin{array}{c}\text { Short } \\
\text { version }\end{array}$ & $\begin{array}{c}\text { Full } \\
\text { version }\end{array}$ & $\begin{array}{c}\text { Short } \\
\text { version }\end{array}$ & Full version & $\begin{array}{c}\text { Short } \\
\text { version }\end{array}$ & $\begin{array}{c}\text { Full } \\
\text { version }\end{array}$ & $\begin{array}{c}\text { Short } \\
\text { version }\end{array}$ & $\begin{array}{c}\text { Full } \\
\text { version }\end{array}$ & $\begin{array}{c}\text { Short } \\
\text { version }\end{array}$ \\
\hline & $\lambda$ (error) & $\lambda$ (error) & $\lambda$ (error) & $\lambda$ (error) & $\lambda$ (error) & $\lambda$ (error) & $\lambda$ (error) & $\lambda$ (error) & $\lambda$ (error) & $\lambda$ (error) \\
\hline $\mathrm{F} 1$ & $.92(.14)$ & & $.94(.10)$ & & $.91(.16)$ & & $.91(.16)$ & & $.94(.11)$ & \\
\hline $\mathrm{F} 2$ & $.81(.33)$ & $.83(.31)$ & $.81(.33)$ & $.81(.33)$ & $.83(.31)$ & $.84(.28)$ & $.81(.33)$ & $.81(.32)$ & $.81(.34)$ & $.82(.31)$ \\
\hline $\mathrm{F} 3$ & $.94(.11)$ & & $.94(.11)$ & & $.94(.11)$ & & $.93(.13)$ & & $.96(.07)$ & \\
\hline $\mathrm{F} 4$ & $.94(.11)$ & $.94(.11)$ & $.93(.12)$ & $.92(.15)$ & $.94(.10)$ & $.96(.07)$ & $.95(.08)$ & $.95(.08)$ & $.93(.13)$ & $.94(.11)$ \\
\hline F5 & $.85(.26)$ & $.87(.22)$ & $.87(.24)$ & $.87(.22)$ & $.85(.27)$ & $.88(.22)$ & $.85(.27)$ & $.88(.22)$ & $.86(.24)$ & $.88(.22)$ \\
\hline F6 & $.94(.10)$ & & $.96(.07)$ & & $.94(.11)$ & & $.97(.05)$ & & $.93(.12)$ & \\
\hline F7 & $.94(.10)$ & & $.95(.09)$ & & $.94(.11)$ & & $.93(.11)$ & & $.95(.09)$ & \\
\hline F8 & $.88(.22)$ & $.86(.25)$ & $.89(.20)$ & $.90(.19)$ & $.87(.23)$ & $.83(.31)$ & $.83(.29)$ & $.79(.36)$ & $.92(.14)$ & $.93(.12)$ \\
\hline F9 & $.93(.13)$ & & $.92(.14)$ & & $.93(.11)$ & & $.96(.06)$ & & $.90(.17)$ & \\
\hline F10 & $.92(.13)$ & $.92(.14)$ & $.90(.17)$ & $.90(.17)$ & $.95(.09)$ & $.94(.11)$ & $.93(.13)$ & $.93(.12)$ & $.92(.13)$ & $.91(.16)$ \\
\hline Reliabilit & & & & & & & & & & \\
\hline$\alpha$ & .97 & .94 & .98 & .94 & .97 & .94 & .97 & .94 & .98 & .95 \\
\hline$\omega$ & .97 & .92 & .97 & .92 & .97 & .93 & .97 & .92 & .98 & .94 \\
\hline
\end{tabular}

Nota. $\lambda=$ factor loadings 
Table 5

Discrimination and difficulty parameters for the items of each dimension

\begin{tabular}{|c|c|c|c|c|c|}
\hline Version of the scale & Item & $\mathrm{a}$ & $\mathrm{b}_{1}$ & $\mathrm{~b}_{2}$ & $\mathrm{~b}_{3}$ \\
\hline \multirow{10}{*}{ Full version } & $\mathrm{F} 1$ & 3.20 & -1.02 & .00 & 1.17 \\
\hline & $\mathrm{F} 2$ & 2.03 & -.07 & .92 & 1.85 \\
\hline & F3 & 3.70 & -.65 & .30 & .99 \\
\hline & $\mathrm{F} 4$ & 4.12 & -.63 & .27 & 1.04 \\
\hline & F5 & 2.21 & -.08 & .73 & 1.69 \\
\hline & F6 & 4.05 & -.66 & .32 & 1.11 \\
\hline & F7 & 3.34 & -1.00 & .09 & .87 \\
\hline & F8 & 2.46 & -.71 & .37 & 1.31 \\
\hline & F9 & 2.96 & -.79 & .22 & 1.05 \\
\hline & F10 & 3.67 & -.54 & .42 & .95 \\
\hline \multirow{5}{*}{ Short version } & F1 & 2.98 & -.25 & .68 & 1.47 \\
\hline & $\mathrm{F} 2$ & 4.15 & -.58 & .25 & .98 \\
\hline & F3 & 3.71 & -.23 & .58 & 1.27 \\
\hline & $\mathrm{F} 4$ & 3.44 & -.67 & .34 & 1.12 \\
\hline & F5 & 4.17 & -.64 & .28 & .86 \\
\hline
\end{tabular}

Note $. \mathrm{a}=$ discrimination parameters; $\mathrm{b}=$ difficulty parameters 


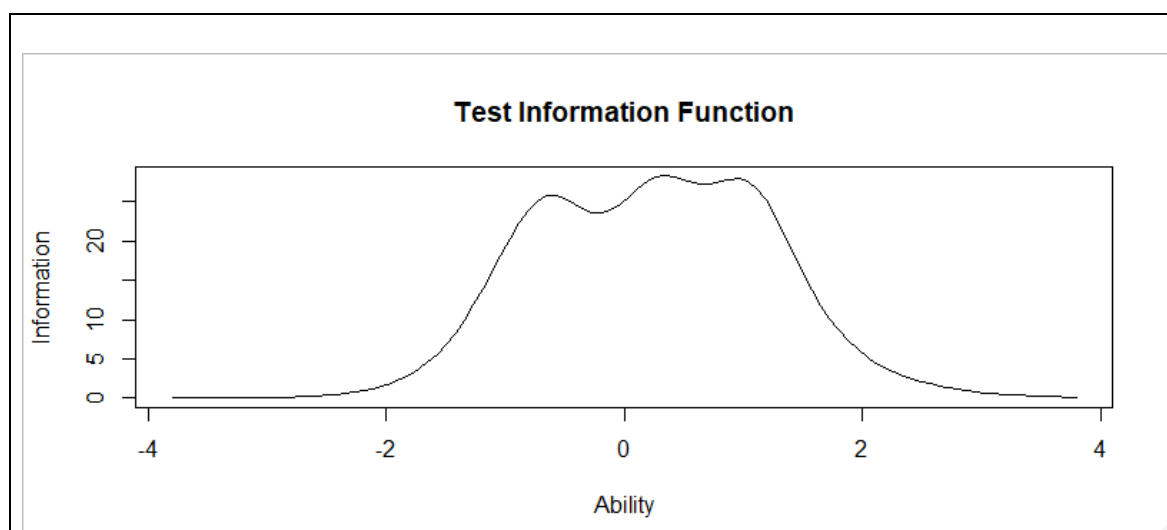

Tests Information Curves (TIC) of the SCSRFQ

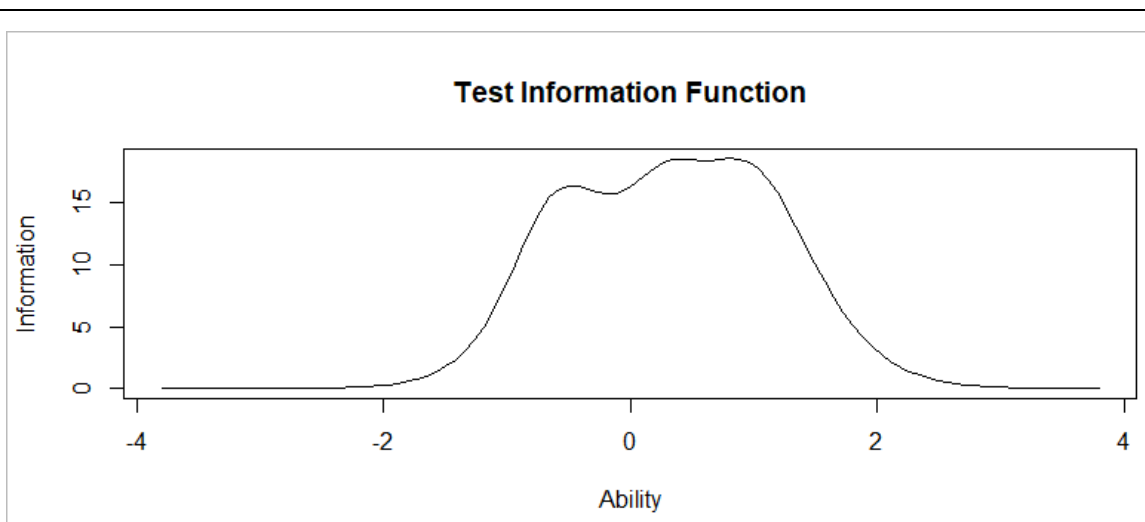

Tests Information Curves (TIC) of the SCSRFQ - Short version

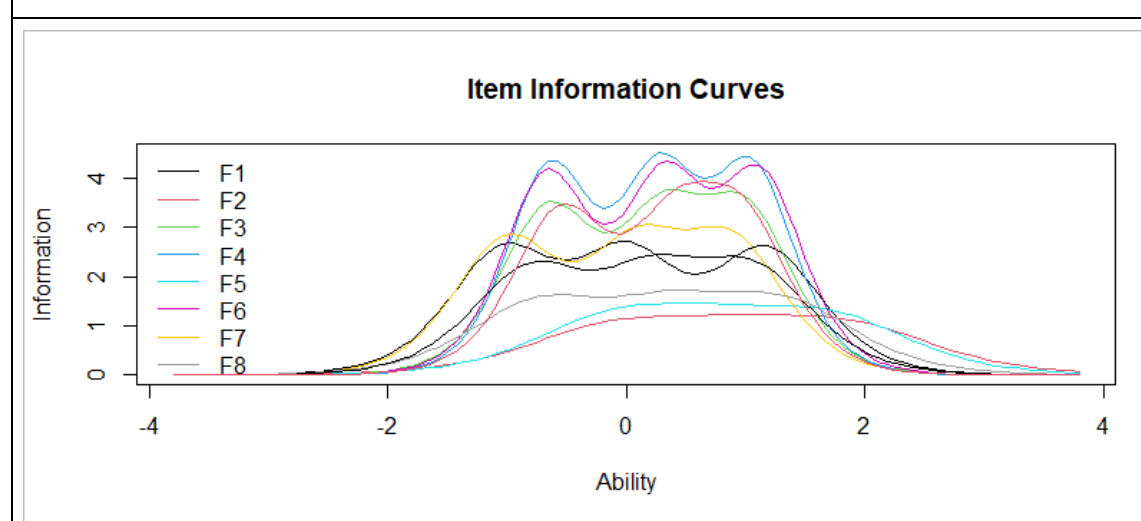

Item Information Curves (IIC) of the SCSRFQ

Item Information Curves

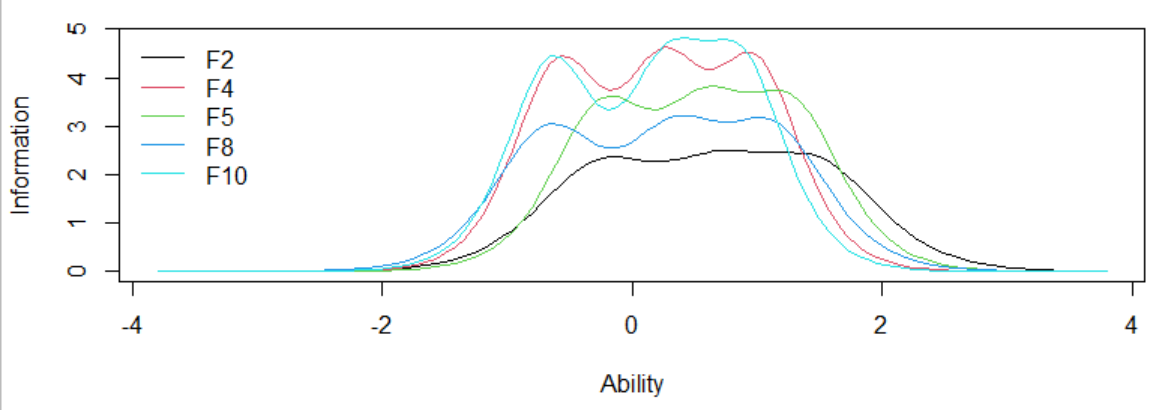

Item Information Curves (IIC) of the SCSRFQ - Short version

Figure 1. Item and Test Information Curves for the Scales 


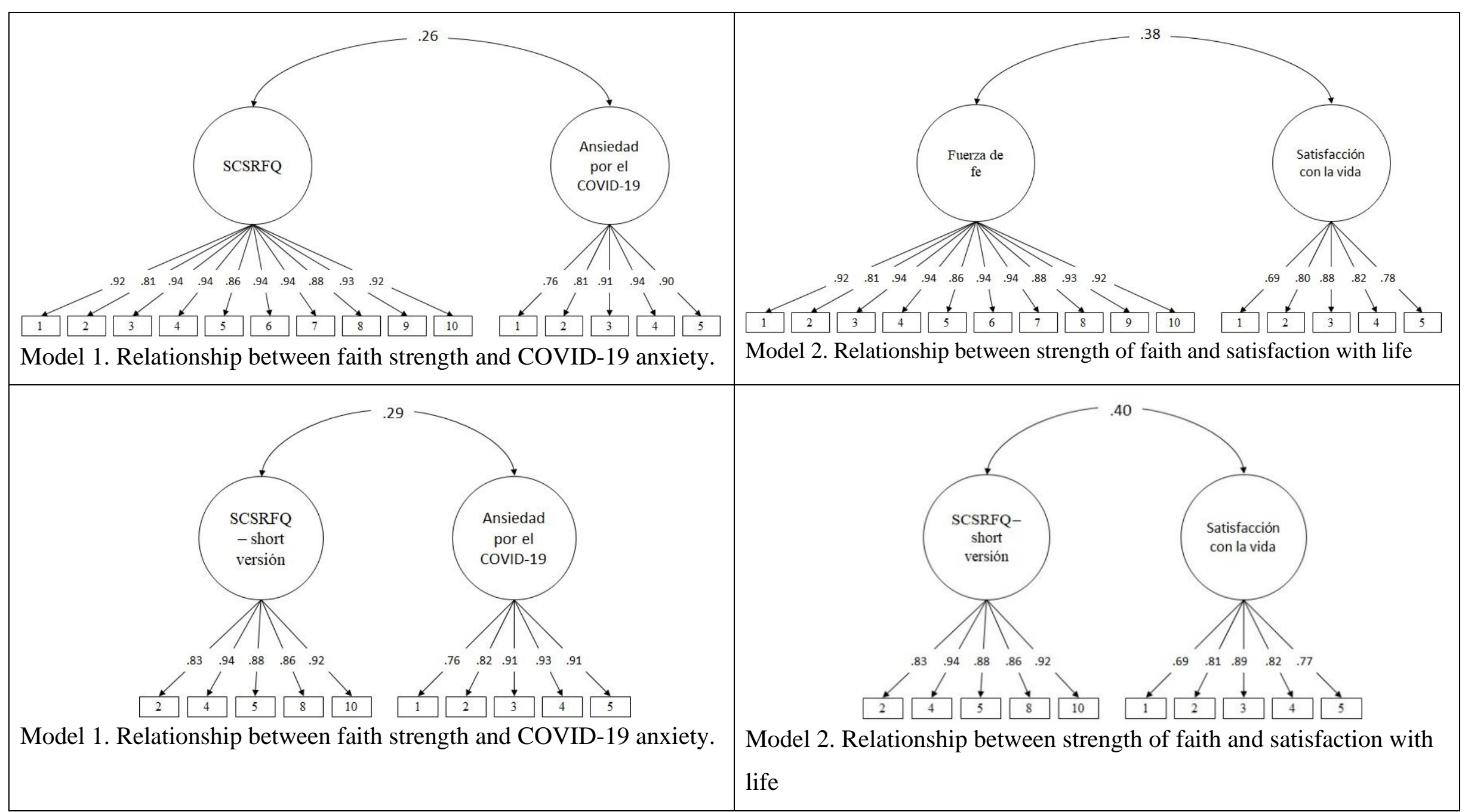

Figure 3. Relationship models of the original and brief version of the SCSRFQ with other constructs. 


\author{
doi:10.20944/preprints202103.0489.v1
}

\author{
Preprints (www.preprints.org) | NOT PEER-REVIEWED | Posted: 18 March 2021

(20)

